\title{
Effect of No-Nitro-L-Arginine Methyl Ester-Induced Intrauterine Growth Restriction on Postnatal Lung Growth in Rats
}

\author{
VÉRONIQUE DIAZ, MARIE-NOELLE LEBRAS-ISABET, AND ANDRÉ DENJEAN \\ Functional Testing, Lung and Exercise Physiology Unit, Poitiers Teaching Hospital, 86021 Poitiers,
} France

\begin{tabular}{|c|c|}
\hline \multicolumn{2}{|c|}{ ABSTRACT } \\
\hline $\begin{array}{l}\text { Infants with intrauterine growth restriction (IUGR) are at high } \\
\text { risk for morbidity and mortality. Preeclampsia, one of the leading } \\
\text { causes of IUGR, begins during the canalicular phase of lung } \\
\text { development. The aim of our study was to determine whether } \\
\text { induced IUGR was responsible for abnormal lung development } \\
\text { in rat pups. We randomized pregnant Sprague-Dawley rats to } \\
\text { daily gavage with either the nitric oxide synthase inhibitor } \\
\mathrm{N} \omega \text {-nitro-L-arginine methyl ester (L-NAME; } n=5,50 \mathrm{mg} \cdot \mathrm{kg}^{-1} \\
\cdot \mathrm{d}^{-1} \text { ) or pure water ( } n=6 \text { ). The pups were weighed at birth and } \\
\text { on postnatal days } 7 \text { and } 14 \text {. At each of these time points, pups } \\
\text { were killed and their lung growth was assessed on the basis of } \\
\text { lung volume and light-microscopy morphometric data. At birth, } \\
\text { body weight, total alveolar surface area, and alveolar surface } \\
\text { density were significantly decreased and alveolar size was sig- } \\
\text { nificantly increased in the L-NAME group, compared with the } \\
\text { control group. On day } 7 \text {, body weight was similar in the two } \\
\text { groups, and the only significant difference was smaller total } \\
\text { alveolar surface area in the L-NAME group. On day } 14 \text {, neither } \\
\text { body weight nor lung morphometric parameters were signifi- }\end{array}$ & $\begin{array}{l}\text { cantly different between the L-NAME group and the controls. } \\
\text { These results suggest that postnatal catch-up growth may com- } \\
\text { pletely correct the lung development disorders present at birth in } \\
\text { IUGR pups, in parallel with the catch-up body weight gain. } \\
\text { (Pediatr Res 58: 557-561, 2005) } \\
\qquad \text { Abbreviations } \\
\text { IUGR, intrauterine growth restriction } \\
\text { Lm, mean linear intercept } \\
\text { L-NAME, N } \omega \text {-nitro-L-arginine methyl ester } \\
\text { NO, nitric oxide } \\
\text { NOS, nitric oxide synthase } \\
\text { PFA, paraformaldehyde } \\
\text { Sa, total alveolar surface area } \\
\text { Sv, alveolar surface density } \\
\text { Valv, mean alveolar volume } \\
\text { VEGF, vascular endothelial growth factor } \\
\text { Vva, air space volume } \\
\text { Vvi, alveolar wall volume }\end{array}$ \\
\hline
\end{tabular}

Studies have established that intrauterine growth restriction (IUGR) is correlated with increased morbidity and mortality (1-3). Despite the huge strides made in neonatal medicine over the past $15 \mathrm{y}$, the risk for respiratory distress syndrome, intraventricular hemorrhage, and necrotizing enterocolitis, as well as length of stay and hospital costs, remain higher in growth-restricted newborns (3). Importantly, the adverse effects of IUGR are long lasting, one of the most common long-term consequences being respiratory disease (4-7).

Preeclampsia is among the leading causes of IUGR. The placental vascular abnormalities associated with preeclampsia impair maternofetal exchanges, thereby restricting fetal growth (8). Impairments in maternofetal exchanges begin during the

Received September 30, 2004; accepted January 19, 2005.

Correspondence: Véronique Diaz, M.D., Ph.D., Service d'explorations fonctionnellesPhysiologie respiratoire et de l'exercice, Pavillon Beauchant-Pôle cœur-poumons, BP 577, 86021 Poitiers Cedex, France; e-mail: v.diaz@chu-poitiers.fr.

DOI: 10.1203/01.PDR.0000179398.62365.43 third trimester of pregnancy, during which lung development is at the canalicular phase, characterized by formation of the distal airways, blood vessels, and alveolar-capillary barrier (9).

Although the pathophysiology of preeclampsia remains unclear, experimental evidence points to a key role for nitric oxide (NO) (10-13). NO synthase (NOS) inhibition during the last third of pregnancy in rats was followed by hypertension and proteinuria in the dams and by IUGR and high fetal mortality in the offspring, a combination that replicated preeclampsia in humans (14-16). In rats, IUGR induced by NOS inhibition was associated with hindlimb necrosis at birth (17). To our knowledge, the long-term development of the offspring was not documented. These data prompted us to assess whether lung development was impaired in rat pups with IUGR induced by NOS inhibition in the dams during gestation.

\section{METHODS}

The study was approved by our institutional review board for animal research. We used 11 pregnant Sprague-Dawley rats (Etablissement Déprés, 
France). Pregnancy was obtained by leaving each female with a male for $12 \mathrm{~h}$ overnight. The next day was taken as the first day of gestation. From day 12 of gestation to the end of the experiments, the pregnant dams were housed in our animal rooms in temperature-controlled units $\left(21 \pm 2^{\circ} \mathrm{C}\right)$ with a $12-\mathrm{h} / 12-\mathrm{h}$ light/dark cycle and free access to food and water. We allocated the rats at random to NOS inhibition or placebo therapy, both given by daily gavage from day 14 to day 21 of gestation. NOS inhibition was induced in five rats by administration of $50 \mathrm{mg} \cdot \mathrm{kg}^{-1} \cdot \mathrm{d}^{-1} \mathrm{~N} \omega$-Nitro-L-arginine methyl ester (L-NAME ). The control group of six rats received pure water.

All dams in both groups littered spontaneously between day 22 and day 23 of gestation; mean duration of pregnancy was similar in the two groups [22.3 $\pm 0.51 \mathrm{~d}$ in the L-NAME group and $22.4 \pm 0.55 \mathrm{~d}$ in the control group $(p>$ $0.05)]$. Neither was litter size different between the two groups [10.3 \pm 3.2 (range, $8-18$ ) in the L-NAME group and $15 \pm 1.5$ (range, 12-17) in the control group; $p>0.05]$. The day of birth was defined as postnatal day 0 . The pups in both groups were kept with their mothers in the cage where they were born. All pups were weighed at birth, then on postnatal days 7 and 14. At each of these three time points, pups were killed and their lungs were harvested for determination of morphometric parameters. Because postnatal growth is influenced by the number of pups per dam, at each time point, we killed the number of rat pups per litter that kept the litter sizes similar; therefore, the number of pups killed varied across time points. In the L-NAME and control groups, litter size was $7.25 \pm 2.8$ and $8 \pm 0.6$ between days 0 and 7 ; it was $7 \pm 0$ and 5.6 \pm 0.8 between days 7 and 14 . In one litter, the pups became dehydrated as a result of insufficient milk production by the dam; this litter was excluded from the analysis on postnatal days 7 and 14. Newborn and 7-d-old pups were killed by decapitation after ether anesthesia and 14-d-old pups by bleeding (renal artery section) after intraperitoneal thiopental anesthesia. The lungs were gently removed and separated from the heart and blood vessels.

Lung volume measurement. A cannula matching the size of the trachea was selected. The cannula was filled with $4 \%$ paraformaldehyde (PFA), inserted into the trachea, and used to inflate the lungs by instilling PFA at a pressure of $20 \mathrm{~cm} \mathrm{H}_{2} \mathrm{O}$. The trachea then was occluded to keep the lungs inflated. Lung volume then was evaluated using the fluid displacement method. Briefly, a vessel partly filled with PFA was weighed, the lungs then were immersed completely in the PFA, and the vessel was weighed again. The weight increase was correlated to the PFA volume displaced by lung immersion. On the basis of the measured weight increase and on the specific gravity of PFA $\left(\sim 1 \mathrm{~g} / \mathrm{cm}^{3}\right)$, we calculated the lung volume (18).

Lung morphometric analysis. The lungs were kept immersed in 4\% PFA for $7 \mathrm{~d}$, that is, until lung retraction stopped. The whole lungs were embedded in paraffin. From each lung, a mediocoronal section $3 \mu \mathrm{m}$ in thickness was cut and stained with hematin, floxin, and saffron. Each lung section was examined under a light microscope connected to a television screen via a color video camera with an overall magnification of $\times 500$. For each field, a grid of 42 points and 21 lines each measuring $3 \mathrm{~cm}$ in length was used (19). We examined 10 fields per lung (i.e. 20 fields per animal) selected by systematic sampling from a random starting point to ensure that the sections were randomly distributed throughout all of the lung lobes. We used a correcting factor of 1.22 to correct the surface area values for the shrinkage caused by our fixation and paraffin-embedding procedure (20). Using the point and intersection counting method (19), we determined the mean linear intercept (Lm; total test-line length/total number of intersections), mean alveolar volume [Valv; $(\mathrm{Lm})^{3} *$ $\Pi / 3]$, percentage of air space volume (Vva), percentage of alveolar wall volume (Vvi), and percentage of lung parenchymal volume (Vva $+\mathrm{Vvi})$. From these data, we computed the total alveolar number [(Vva* VL)/Valv], alveolar surface density (i.e. alveolar wall area per unit of alveolar volume: $\mathrm{Sv}=$ $2 / \mathrm{Lm})$, total alveolar surface area $[\mathrm{Sa}=4 *(\mathrm{Vva}+\mathrm{Vvi}) * \mathrm{VL} / \mathrm{Lm}]$, and alveolar wall thickness $[(\mathrm{Vvi} * \mathrm{VL}) / \mathrm{Sa}](21)$.

Statistical analysis. Data are expressed as means \pm SD. The values in the two groups were compared at each time point using the Mann-Whitney $U$ test run on StatView 4.01 (Abacus Concepts Inc., Berkley, CA).

\section{RESULTS}

Rat pups at birth. We obtained 84 live newborn rat pups in the control group and 56 in the L-NAME group. In this last group, three of the 56 pups had hindlimb necrosis. The three stillborn rat pups in the control group and four in the L-NAME group were excluded from further analysis. The body weight at birth was significantly lower in the L-NAME group [5.46 \pm $0.5 \mathrm{~g}$ (range, $4.3-6.6)]$ than in the control group [6.21 $\pm 0.55 \mathrm{~g}$ (range, 4.3-7.5); $p<0.0001$; Fig. 1].
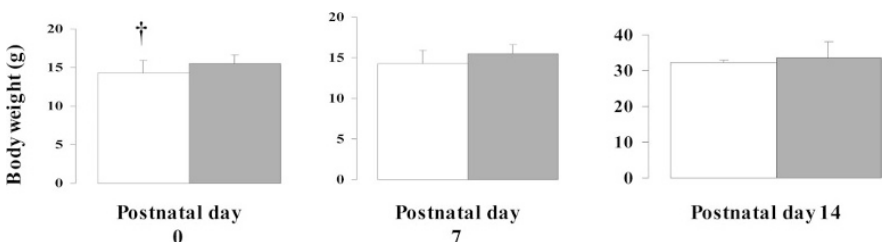

Figure 1. Body weight at 0,7 , and $14 \mathrm{~d}$ of postnatal life in L-NAME ( $\square$ ) and Control (ם) rat pups. $\dagger p<0.05$ vs controls.

Lung morphometric data at birth. Under the light microscope, increased alveolar size consistent with delayed lung development was noted in the L-NAME group compared with the control group (Fig. 2). Table 1 reports the lung morphometry data at birth, which were obtained from 23 pups in the control group and 12 pups in the L-NAME group. Compared with the controls, the newborn pups from dams that were given L-NAME exhibited significant decreases in $\mathrm{Sa}(p=0.0165)$ and $\mathrm{Sv}(p=0.0075)$ and a significant increase in $\operatorname{Lm}(p=$ $0.006)$ and Valv $(p=0.0033)$. Although the differences were not significant, trends toward lower values for lung volume and alveolar number were noted in the L-NAME pups.

Findings on postnatal days 7 and 14. On postnatal days 7 and 14, body weights were similar in the L-NAME and control groups $(p>0.05)$. As shown in Fig. 2, the pulmonary morphometric differences between the L-NAME and control groups were less marked on postnatal day 7 than at birth. Thus, on postnatal day 7 , Sa was smaller $(p=0.04)$ in the L-NAME pups (203 \pm 39$)$ than in the control pups $(244 \pm 20)$, although lung volume was similar in the two groups $(0.775 \pm 0.149$ in

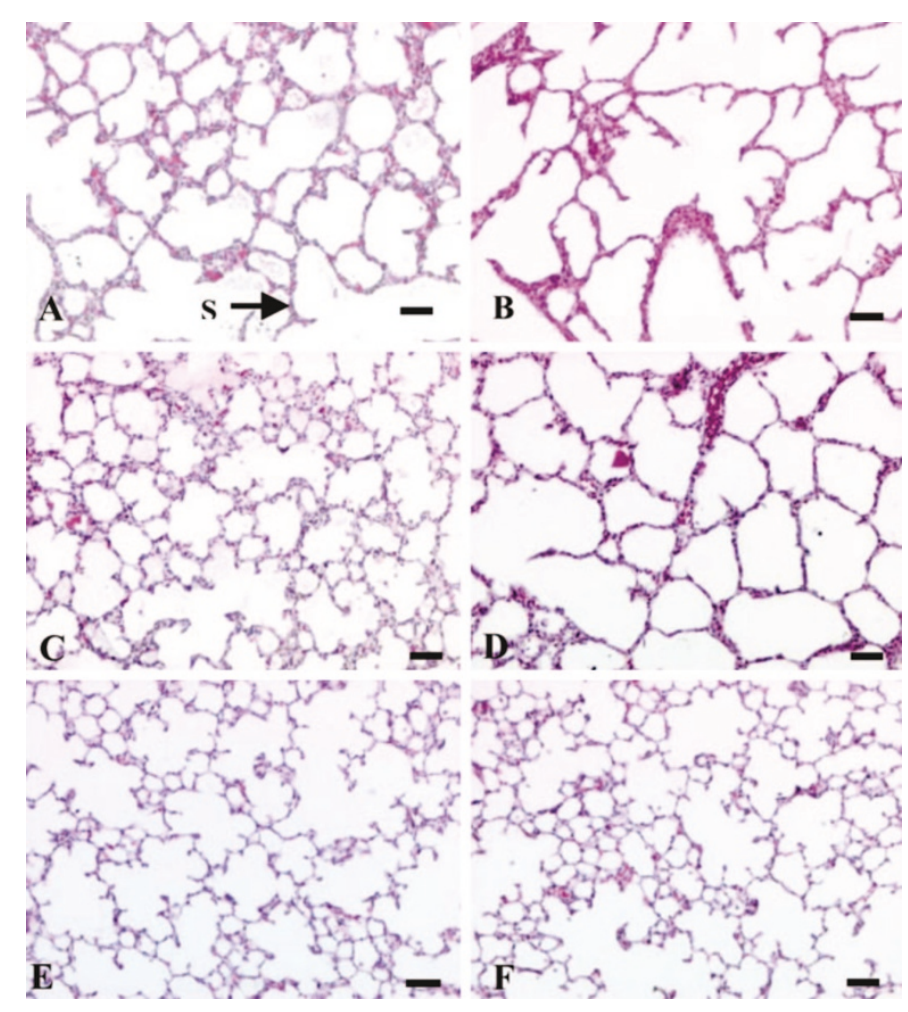

Figure 2. Lung appearance under light microscope respectively in control and L-NAME rat pups at birth $(A$ and $B), 7 \mathrm{~d}(C$ and $D)$, and $14 \mathrm{~d}(E$ and $F)$ of postnatal life. Bar $=40 \mu \mathrm{m}$. The arrow indicates septa (S). 
Table 1. Lung Morphometry Data

\begin{tabular}{|c|c|c|}
\hline & \multicolumn{2}{|c|}{ Birth } \\
\hline & L-NAME & Control \\
\hline BW (g) & $5.46 \pm 0.5(\mathrm{n}=56) \dagger$ & $6.21 \pm 0.55(\mathrm{n}=84)$ \\
\hline LV (ml) & $0.296 \pm 0.096(\mathrm{n}=12)$ & $0.35 \pm 0.069(\mathrm{n}=23)$ \\
\hline $\operatorname{Lm}(\mu \mathrm{m})$ & $96 \pm 11(\mathrm{n}=12) \dagger$ & $84 \pm 13(n=23)$ \\
\hline $\mathrm{Sa}\left(\mathrm{cm}^{2}\right)$ & $63.3 \pm 20(\mathrm{n}=12) \dagger$ & $84.4 \pm 20(n=23)$ \\
\hline Sva $\left(\mathrm{cm}^{2} / \mathrm{cm}^{3}\right)$ & $218 \pm 21(\mathrm{n}=12) \dagger$ & $251 \pm 39(\mathrm{n}=23)$ \\
\hline Valv $\left(10^{-6} \mathrm{~cm}^{3}\right)$ & $1.13 \pm 0.49(\mathrm{n}=12) \dagger$ & $0.74 \pm 0.36(\mathrm{n}=23)$ \\
\hline Nalv $\left(10^{6}\right)$ & $0.29 \pm 0.16(\mathrm{n}=12)$ & $0.43 \pm 0.18(n=23)$ \\
\hline $\mathrm{T}(\mu \mathrm{m})$ & $15.5 \pm 4(n=12)$ & $16.2 \pm 3.8(\mathrm{n}=23)$ \\
\hline $\mathrm{Sa} / \mathrm{BW}\left(\mathrm{cm}^{2} / \mathrm{g}\right)$ & $12 \pm 3.9(\mathrm{n}=12)$ & $13.5 \pm 3.4(\mathrm{n}=23)$ \\
\hline LV/BW (ml/g) & $0.06 \pm 0.016(\mathrm{n}=12)$ & $0.057 \pm 0.01(\mathrm{n}=23)$ \\
\hline
\end{tabular}

\begin{tabular}{|c|c|c|}
\hline & \multicolumn{2}{|c|}{ Postnatal day 7} \\
\hline & L-NAME & Control \\
\hline BW (g) & $14.3 \pm 1.6(\mathrm{n}=11)$ & $15.5 \pm 1.1(\mathrm{n}=5)$ \\
\hline LV (ml) & $0.78 \pm 0.15(\mathrm{n}=11)$ & $0.84 \pm 0.12(\mathrm{n}=5)$ \\
\hline $\operatorname{Lm}(\mu \mathrm{m})$ & $68 \pm 6(n=11)$ & $76 \pm 8(\mathrm{n}=5)$ \\
\hline $\mathrm{Sa}\left(\mathrm{cm}^{2}\right)$ & $203 \pm 39(\mathrm{n}=11) \dagger$ & $244 \pm 20(\mathrm{n}=5)$ \\
\hline Sva $\left(\mathrm{cm}^{2} / \mathrm{cm}^{3}\right)$ & $275 \pm 30(\mathrm{n}=11)$ & $300 \pm 21(\mathrm{n}=5)$ \\
\hline Valv $\left(10^{-6} \mathrm{~cm}^{3}\right)$ & $0.52 \pm 0.18(\mathrm{n}=11)$ & $0.368 \pm 0.1(\mathrm{n}=5)$ \\
\hline Nalv $\left(10^{6}\right)$ & $1.25 \pm 0.41(\mathrm{n}=11)$ & $1.53 \pm 0.36(\mathrm{n}=5)$ \\
\hline $\mathrm{T}(\mu \mathrm{m})$ & $14.3 \pm 3.6(n=11)$ & $14.7 \pm 3.2(\mathrm{n}=5)$ \\
\hline $\mathrm{Sa} / \mathrm{BW}\left(\mathrm{cm}^{2} / \mathrm{g}\right)$ & $14 \pm 2.37(\mathrm{n}=11)$ & $15.7 \pm 1.19(\mathrm{n}=5)$ \\
\hline \multirow[t]{3}{*}{ LV/BW (ml/g) } & $0.054 \pm 0.008(\mathrm{n}=11)$ & $0.054 \pm 0.009(\mathrm{n}=5)$ \\
\hline & \multicolumn{2}{|c|}{ Postnatal day 14} \\
\hline & L-NAME & Control \\
\hline BW (g) & $32.2 \pm 0.6(n=6)$ & $33.7 \pm 4.4(\mathrm{n}=13)$ \\
\hline LV (ml) & $1.39 \pm .014(\mathrm{n}=6)$ & $1.38 \pm 0.18(\mathrm{n}=13)$ \\
\hline $\operatorname{Lm}(\mu \mathrm{m})$ & $63 \pm 2(n=6)$ & $61 \pm 5(n=13)$ \\
\hline $\mathrm{Sa}\left(\mathrm{cm}^{2}\right)$ & $441 \pm 38(n=6)$ & $450 \pm 66(n=13)$ \\
\hline Sva $\left(\mathrm{cm}^{2} / \mathrm{cm}^{3}\right)$ & $339 \pm 13(n=6)$ & $339 \pm 30(n=13)$ \\
\hline Valv $\left(10^{-6} \mathrm{~cm}^{3}\right)$ & $0.34 \pm 0.063(n=6)$ & $0.27 \pm 0.063(\mathrm{n}=13)$ \\
\hline Nalv $\left(10^{6}\right)$ & $4.98 \pm 0.38(\mathrm{n}=6)$ & $4.53 \pm 1.17(\mathrm{n}=13)$ \\
\hline $\mathrm{T}(\mu \mathrm{m})$ & $8.6 \pm 1.3(\mathrm{n}=6)$ & $10 \pm 2(\mathrm{n}=13)$ \\
\hline $\mathrm{Sa} / \mathrm{BW}\left(\mathrm{cm}^{2} / \mathrm{g}\right)$ & $13.7 \pm 1.24(\mathrm{n}=6)$ & $13.47 \pm 1.25(\mathrm{n}=13)$ \\
\hline LV/BW (ml/g) & $0.043 \pm 0.004(\mathrm{n}=6)$ & $0.041 \pm 0.005(\mathrm{n}=13)$ \\
\hline
\end{tabular}

Rat pups body weight (BW), lung volume (LV) and lung morphometric parameters including mean linear intercept $(\mathrm{Lm})$, total alveolar surface area (Sa), alveolar surface density (Sva), alveolar volume (Valv), number of alveoli (Nalv), alveolar wall thickness (T) and the ratios total alveolar surface area/ body weight $(\mathrm{Sa} / \mathrm{BW})$ and lung volume/body weight $(\mathrm{LV} / \mathrm{BW})$ at birth, 7 and 14 days of age.

$\dagger, \mathrm{p}<0.05$ vs. CTRL.

the L-NAME group versus $0.84 \pm 0.123$ in the control group). Valv was greater in the L-NAME pups, but the difference with the controls was no longer significant. On postnatal day 14, none of the morphometric parameters was significantly different between the L-NAME and control groups.

\section{DISCUSSION}

Our study confirmed that administration of the NOS inhibitor L-NAME during the last $7 \mathrm{~d}$ of pregnancy in rats caused IUGR in the pups. At birth, IUGR was associated with a significant delay in lung development, manifesting as decreases in lung volume, Sa, and Sv, with an increase in Valv. However, these lung growth differences between the L-NAME and control groups resolved within the first 2 postnatal wk, as did the difference in body weight.
Consequences of L-NAME treatment on rat pups' growth in utero. As previously described, we observed in the LNAME group a significant decrease in the pups' birth weight, compared with the controls. Trophoblast-derived NO seems involved in the pathophysiology of preeclampsia, although its exact role in the control of human placental function remains unclear. The hypothesis that endothelial dysfunction may cause preeclampsia has received support from studies showing abnormal levels of NOS in placental umbilical artery endothelium from women with preeclampsia (10-13). Furthermore, studies of perfused human fetal placentas have established that NO contributes to maintain a low vascular resistance (22). In our experiments, inhibition by L-NAME of NO-induced vasodilation probably altered the placental blood flow, thereby impairing transplacental maternofetal exchanges and ultimately inducing fetal growth restriction.

Lung morphometric methods. In this study, lung morphometric analysis was performed using classical stereologic methods in which Lm is obtained with a nonuniform sample of alveolar profiles. New morphometric procedures using dissector method (23) combined with the selector method (24) or with a connectivity estimator (25) allow unbiased determination of alveolar number and size. The disadvantage of the classical method that we used is that on a single thin section of lung, the probability of alveoli to be represented is proportional to their height perpendicular to the section plane. Despite that the technique that we used is widely recognized, our results thus could have been somewhat biased. However, the same technique was used in both groups and at all experimental steps; the differences that we observed are clearly significant at birth, and the results that we obtained at birth and 7 and $14 \mathrm{~d}$ of life are consistent with the aspect of lung under light microscope.

Consequences of L-NAME treatment on lung development in utero. We found a significant decrease in $\mathrm{Sa}$ in the pups that were exposed to L-NAME during the last third of their fetal life. Although this difference was not significant when Sa was corrected for body weight, the significant decrease in $\mathrm{Sv}$ and significant increase in Valv in the L-NAME pups compared with the controls were consistent with lung growth impairment induced by L-NAME administration.

In the present study, L-NAME was given from day 14 to day 21 of gestation, which covers the entire canalicular phase and part of the saccular phase of lung development. The decrease in $\mathrm{Sv}$ and increase in Valv observed at birth in the L-NAME rats therefore may be ascribable to impairment of formation of the distal airspaces usually observed during the saccular phase of lung development.

Consequences on lung development were already described in a previous study on rat pups that were exposed to L-NAME in utero; the authors observed that the fetal lung/body weight ratio was significantly lower, suggesting delayed lung growth, compared with control pups (26). Several hypotheses can be suggested to explain the consequences of our L-NAMEinduced IUGR on lung development at birth in rat pups. First, as discussed above, L-NAME administration may have interfered with lung development simply by impairing maternofetal exchanges. Other methods of experimental IUGR, such as 
uteroplacental embolization in pregnant ewes, caused impairments in bronchial growth (27) at birth and significantly reduced functional residual capacity, total lung capacity at $30 \mathrm{~cm}$ $\mathrm{H}_{2} \mathrm{O}$, diffusing capacity of the lung for carbon monoxide, and compliance of the respiratory system from birth to $8 \mathrm{wk}$ of postnatal age in lambs (28). Moreover, gas exchange surface area, oxygen uptake, and body weight are strongly correlated in mammals (29). Indeed, in mice, gas exchange surface area increases with oxygen uptake (30). Furthermore, in rats, oxygen uptake diminishes with calorie restriction and increases with subsequent refeeding (31). In our study, the effects of L-NAME treatment on whole-body metabolism also could have interfered with lung development. Finally, it has been suggested that the hemorrhagic necrosis of the fetal hindlimbs observed after oral L-NAME administration to the dam may be related to inhibition of fetal NO synthesis by L-NAME having crossed the placenta (32). Vascular endothelial growth factor (VEGF) is recognized as a key factor in lung angiogenesis. In newborn rats, inhibition of VEGF receptors decreases lung vascular growth and alveolization (33) and down-regulates endothelial NOS expression (34). Inhalation of NO improves lung vascular and alveolar growth in newborn rats that are treated with VEGF receptor inhibitor (34). NO thus is a downstream VEGF effector essential in lung vascular and alveolar growth. In our experiments, the effects of L-NAME treatment on lung growth at birth could also be due to decreased distal lung microvascular development caused by NO synthase inhibition during fetal development.

Postnatal changes in the rat pups. During the first $2 \mathrm{wk}$ of life, all pups remained in the cage where they were born, with their mother, which had free access to food and water and received no further treatment. Litter size was kept similar between the two groups to avoid differences related to the amount of milk available from the mothers. During this period, pups usually experience a phase of rapid alveolization followed by a phase of slower production of additional alveoli until adulthood (9). We observed rapid catch-up in body weight of the L-NAME pups compared with the controls, together with abolition of the differences in lung morphometric parameters during the first 2 postnatal wk. These results suggest that the formation of secondary septa during the rapid alveolization phase was unimpaired, despite the earlier disturbance in lung development.

Discrepancy with previous data on postnatal lung changes in low birth weight animals and humans. The rapid and complete catch-up growth that abolished differences in lung morphometric parameters in our study is somewhat surprising given earlier data on pulmonary outcomes in low birth weight humans and animals, particularly lambs. In humans, IUGR was correlated with decreased forced expiratory flows and volumes in infancy (5). A retrospective cohort study reported in 1993 showed that children who had IUGR at birth exhibited lung function impairments at 5-11 y of age; respiratory wheezy illness, in contrast, was correlated with preterm birth rather than with IUGR (6). Another study found that low birth weight was correlated with an increased risk for respiratory disorders in adulthood (7).
In a model of IUGR induced by uteroplacental embolization in ewes, the lambs showed impaired lung development, with decreased numbers of large alveoli having thick alveolar septa (4). These abnormalities worsened from birth to $8 \mathrm{wk}$ of postnatal age and were still present in 2-y-old adults (4), suggesting a default in alveolarization.

Our results seem to contradict these earlier findings. Differences in the timing of lung development across species may explain, at least in part, the discrepancies across humans, lambs, and rats. Alveolization begins a few weeks before birth in humans and lambs but starts only after birth in rats. Thus, the discrepancy between our results and those in humans and lambs may be ascribable to correction of the body growth deficiency before the alveolar phase of lung development in our full-term rat pups.

Studies in adult mice showed that calorie restriction was associated with a decrease in alveolar surface area, a decrease in alveolar number, and an increase in alveolar size; all of these abnormalities were reversible after refeeding (35). These results are consistent with our findings in newborn rat pups. The difference between our findings and those obtained in lambs may also be ascribable to differences in the potential for lung regeneration between the two species.

\section{CONCLUSION}

Our results in rat pups show that IUGR induced by L-NAME is associated with delayed lung growth at birth followed by a full recovery during the rapid alveolization phase in parallel with body weight normalization. Thus, a plausible hypothesis is that pulmonary outcomes may be influenced by neonatal nutrition in human infants with IUGR.

Acknowledgments. We thank Christophe Delacourt and Marie-Laure Franco for help with the morphometric analysis of the lungs and Christine Richer for assistance in inducing hypertension and measuring blood pressure in the pregnant rats.

\section{REFERENCES}

1. Ounsted M, Moar V, Scott WA 1981 Perinatal morbidity and mortality in small-fordates babies: the relative importance of some maternal factors. Early Hum Dev 5:367-375

2. Kramer MS, Olivier M, Mc Lean FH, Willis DM, Usher RH 1990 Impact of intrauterine growth retardation and body proportionality on fetal and neonatal outcome. Pediatrics 86:707-713

3. Gilbert WM, Danielsen B 2003 Pregnancy outcomes associated with intrauterine growth restriction. Am J Obstet Gynecol 188:1596-1601

4. Maritz GS, Cock ML, Louey S Joyce BJ, Albuquerque CA, Harding R 2001 Effects of fetal growth restriction on lung development before and after birth: a morphometric analysis. Pediatr Pulmonol 32:201-210

5. Lum S, Hoo AF, Dezateux C, Wade A, DeRooy L, Costeloe R, Stocks J 2001 The association between birthweight, sex, and airway function in infants of nonsmoking mothers. Am J Respir Crit Care Med 164:2078-2084

6. Rona RJ, Gulliford MC, Chinn S 1993 Effects of prematurity and intrauterine growth on respiratory health and lung function in childhood. BMJ 306:817-820

7. Barker DJ, Godfrey KM, Fall C, Osmond C, Winter PD, Shaheen SO 1991 Relation of birth weight and childhood respiratory infection to adult lung function and death from chronic obstructive airway disease. BMJ 303:671-675

8. Friedman SA, Taylor RN, Roberts JM 1991 Pathophysiology of preeclampsia. Clin Perinatol 18:661-682

9. Burri PH 1999 Lung development and pulmonary angiogenesis. In: Gaultier C, Bourbon J, Post M (eds) Lung Development. Oxford University Press, New York, pp $122-151$ 
10. Rutherford RA, McCarthy A, Sullivan MH, Elder MG, Polak JM, Wharton J 1995 Nitric oxide synthase in human placenta and umbilical cord from normal, intrauterine growth-retarded and pre-eclamptic pregnancies. Br J Pharmacol 119:3099-3109

11. Lyall F, Young A, Greer IA 1995 Nitric oxide concentrations are increased in the fetoplacental circulation in preeclampsia. Am J Obstet Gynecol 173:714-718

12. Myatt L, Eis AL, Brockman DE, Greer IA, Lyall F 1997 Endothelial nitric oxide synthase in placental villous tissue from normal, pre-eclamptic and intrauterine growth-restricted pregnancies. Hum Reprod 12:167-172

13. Myatt L, Eis AL, Brockman DE, Kossenjans W, Greer I, Lyall F 1997 Inducible (type II) nitric oxide synthase in human placental villous tissue of normotensive, preeclamptic and intrauterine growth-restricted pregnancies. Placenta 18:261-268

14. Yallampalli C, Garfield RE 1993 Inhibition of nitric oxide synthesis in rats during pregnancy produces signs similar to those of preeclampsia. Am J Obstet Gynecol 169:1316-1320

15. Richer C, Boulanger H, Es-Slami S, Giudicelli JF 1996 Lack of beneficial effects of the NO-donor, molsidomine, in the L-NAME-induced pre-eclamptic syndrome in pregnant rats. Br J Pharmacol 119:1642-1648

16. Kassab S, Miller MT, Hester R, Novak J, Granger JP 1998 Systemic hemodynamics and regional blood flow during chronic nitric oxide synthesis inhibition in pregnant rats. Hypertension 31:315-320

17. Fantel AG, Nekahi N, Shepard TH, Cornel LM, Unis AS, Lemire RJ 1997 The teratogenicity of $\mathrm{N} \omega$-nitro-L-arginine methyl ester (L-NAME), a nitric oxide synthase inhibitor in rats. Reprod Toxicol 11:709-717

18. Scherle W 1970 A simple method for volumetry of organs in quantitative stereology. Mikroskopie 26:57-60

19. Weibel ER, Cruz-Orive LM 1997 Morphometric methods. In: Crystal RG, West JB, Weibel ER, Barnes PJ (eds) The Lung. Scientific Foundations, 2nd Ed. LippincottRaven, Philadelphia, pp 333-344

20. Franco ML, Waszak P, Banalec G, Levame M, Lafuma C, Harf A, Delacourt C 2002 LPS-induced lung injury in neonatal rats: changes in gelatinase activities and consequences on lung growth. Am J Physiol 282:L491-L500

21. Maritz GS, Cock ML, Louey S, Suzuki K, Harding R 2004 Fetal growth restriction has long-term effects on postnatal lung structures in sheep. Pediatr Res 55:287-295

22. Myatt L, Brewer A, Brockman DE 1991 The action of nitric oxide in the perfused human-fetal placental circulation. Am J Obstet Gynecol 164:687-692

23. Sterio DC 1984 The unbiased estimation of number and size of arbitrary particles using the disector. J Microsc 134:127-136
24. Massaro GD, Massaro D 1996 Formation of pulmonary alveoli and gas-exchange surface area: quantitation and regulation. Annu Rev Physiol 58:73-92

25. Ochs M, Nyengaard JR, Jung A, Knudsen L, Voigt M, Wahlers T, Richter J, Gundersen HJ 2004 The number of alveoli in the human lung. Am J Respir Crit Care Med 169:120-124

26. Greenberg SS, Lancaster JR, Xie J, Sarphie TG, Zhao X, Hua L, Freeman T, Kapusta DR, Giles TD, Powers DR 1997 Effects of NO synthase inhibitors, arginine-deficient diet and amiloride in pregnant rats. Am J Physiol 273:R1031-R1045

27. Wignarajah D, Cock ML, Pinkerton KE, Harding R 2002 Influence of intrauterine growth restriction on airway development in fetal and postnatal sheep. Pediatr Res 51:681-688

28. Joyce BJ, Louey S, Davey MG, Cock ML, Hooper SB, Harding R 2001 Compromised respiratory function in postnatal lambs after placental insufficiency and intrauterine growth restriction. Pediatr Res 50:641-649

29. Weibel ER 1979 Oxygen demand and the size of respiratory structures in mammals. In: Wood SC (ed) Evolution of the Respiratory Processes. Marcel Dekker, New York, pp 289-345

30. Hugonnaud C, Gehr P, Weibel ER, Burri PH 1977 Adaptation of the growing lung to increased oxygen consumption II. Morphometric analysis. Respir Physiol 29:1-10

31. Munch IC, Markussen NH, Oritsland NA 1993 Resting oxygen consumption in rats during food restriction, starvation and refeeding. Acta Physiol Scand 148:335340

32. Diket AL, Pierce MR, Munshi UK, Voelker CA, Eloby-Childress S, Greenberg SS, Zhang XJ, Clark DA, Miller MJ 1994 Nitric oxide inhibition causes intrauterine growth retardation and hind-limb disruptions in rats. Am J Obstet Gynecol 171:12431250

33. Jakkula M, Le Cras TD, Gebb S, Hirth KP, Tuder RM, Voelkel NF, Abman SH 2000 Inhibition of angiogenesis decreases alveolarization in the developing rat lung. Am J Physiol 279:L600-L607

34. Tang JR, Markham NE, Lin YJ, McMurtry IF, Maxey A, Kinsella JP, Abman SH 2004 Inhaled nitric oxide attenuates pulmonary hypertension and improves lung growth in infant rats after neonatal treatment with a VEGF receptor inhibitor. Am J Physiol 287:L344-L351

35. Massaro GD, Radaeva S, Clerch LB, Massaro D 2002 Lung alveoli: endogenous programmed destruction and regeneration. Am J Physiol 283:L305-L309 